\title{
5. New Media in the Electoral Context: The new normal
}

\author{
Peter John Chen
}

The political impact and use of new media technologies - the internet, social media and mobile communication - have been subject to specific attention in the coverage of federal elections for nearly a decade now. Over this time, the use of new media has moved from being a novelty for parties, candidates, civil society organisations and established media to becoming an important - if still secondary - aspect of political communication in the electoral process. This new significance is seen in the professionalisation of channel management by political actors, heightened risk management by political organisations, and increased use of international knowledge transfer and learning. These changes represent an example of the adaptation of wholly new communication technologies into the political environment, and the interplay between technological possibilities and the structural context (Gibson 2002; Chen 2013).

Building on this tradition, this chapter examines the role of new media in the 2013 campaign, focusing on the use of online media channels by central party campaign teams and in the news media. Following Gibson and Cantijoch's (2011) question about the role of new media in the 2010 election, I argue that new media has finally 'arrived' as an essential element of the contemporary electoral practices of Australian political parties, with visible and significant impacts on the conduct of the 2013 election and elections to come. This has significant political implications for the competitiveness and representation of electoral politics, albeit constrained by Australia's two-party system. The chapter identifies the way established parliamentary parties are able to rapidly adopt new techniques and co-opt practices from civil society groups, entrenching the political status quo in a changing media landscape. In other words, the chapter provides evidence of the 'normalisation hypothesis' of political adoption of new technology (Gibson and McAllister 2011). At the same time, interesting developments in the reporting of elections are occurring within parts of the Australian news media that may be challenging the way parties are able to act as 'primary definers' of policy issues. 


\section{Political parties: Channel integration, cash and co-option}

During the past decade, different elections have seen specific new media channels (sub-media) highlighted as areas of specific innovation and public attention. The late 1990s and early 2000s saw a focus on the deployment of campaign websites (Gibson 2002), the 2007 election was notable for the use of YouTube and social networking services (Chen 2008), and the 2010 election saw considerable attention devoted to the role of micro-blogging service Twitter (Macnamara and Kenning 2011). While often useful tools in positioning (branding) parties and candidates through association with technical sophistication and capability, these innovations tended to remain peripheral to campaign strategy in terms of both presentation and organisational management (Gibson and Cantijoch 2011: 8-9).

The 2013 election is distinct from this pattern in that the use of a wide range of online channels by the established parliamentary parties was undertaken using integrated multi-channelling. Multi-channelling in this context is defined as 'the use of more than one channel or medium to manage customers in the way that is consistent and coordinated across all the channels or media used' (Hobbs et al. 2003: 316). This approach is synergistic: maximising the benefits of individual sub-media through combining their strengths and mitigating weaknesses. While this has been seen in previous elections (particularly the use of email and SMS messaging to drive key audiences like journalists to webpages), in 2013 a wider range of channels were employed, including email, search and display advertising, and social media. ${ }^{1}$ The sources of this change result from the significance parties are placing on new media as primary campaigning tools, and their willingness to engage in pro-active learning from a range of sources.

\section{Getting serious about new media}

In lead-up to the 2013 campaign, the Australian Labor Party (ALP), Liberal Party of Australia (Liberals) and Australian Greens (Greens) displayed a far more disciplined and instrumental approach to the management of new media communications. This is reflected in decisions to increase levels of expenditure on online advertising, systems acquisition and staff, to reduce the visibility of candidates through discouraging their use of some channels (the Liberal Party; Wright 2012), as well as increasing the organisational importance of new media managers within the core campaign team (personal interviews: Skye Laris,

1 The term 'social media' is generally used to describe services like Twitter, Facebook and blogs (though see Kaplan and Haenlein 2010 for a more complex definition). 
ALP Director of Digital Communications, Organising and Campaigns, 23 July 2013; Rosanne Bersten, Australian Greens National Digital Communications Coordinator, 2 August 2013).

While social media channels have been used to a degree in previous campaigns (although with a strong preference towards more 'top-down' communications methods by the major parties; Grant et al. 2010), the 2013 campaign saw these parties become much more active in these areas (Loughnane 2013). There was recognition of the considerable benefits social media channels can bring in linking political communication with audience action. In addition, while uncertainty has tended to encourage isomorphism of application in previous elections, the ends-directed nature of planning for the 2013 campaign saw considerable divergence in the way the parties deployed new media. This is evident in the different use of 'push' channels by the two major parties: the ALP making greater use of targeted email, while the Liberals used more targeted advertising on Facebook. Additionally, the ALP tended to focus on the figure of the leader (and through him, downplay the party), while the Liberals highlighted the party over the leader (see the arguments of Strangio and Walter in Chapter 3, this volume). In this context, Kevin Rudd's continual use of 'selfie' photographs with members of the public contrasts with the Liberals' use of the party brand and promotion of the new Liberal 'team' over highly personalised messaging.

Each of these parties benefited considerably from a more managerial approach, avoiding the use of 'gimmicks' that might have been employed under previous management approaches (such as phone apps that have unproven value in spite of rapid smartphone adoption; see Sadauskas 2013), preferring instead strategies based on clear cost-benefit terms. Overall, the Liberals won both the election and the 'visibility war', outperforming their rivals in driving traffic to their website through both search engines and via social media channels. As in previous years, the Greens have a higher online visibility than their primary vote would suggest (Grant et al. 2008), reflecting the tendency for Greens supporters to be correlated with attributes associated with higher levels of internet uptake and intensity of use (education, urban living). Following Small's (2008) observation of the Canadian electoral context, minor parties may be able to have an online presence equivalent to that of the established parties, but this does not automatically lead to heightened levels of visibility; constituency and strategy is critical in overcoming the structural advantages of parties of government. 
The strong new media performance of the Liberals is illustrated in Table 1: the Liberals were more effective in driving traffic to their site than the ALP. ${ }^{2}$ Significantly, they were able to achieve this at lower cost in search engine advertising than the ALP, and to attract more than three times the rate of referrals via social media sources. The Liberals also used online video more effectively and were far more visible on Facebook. While Kevin Rudd was able to dominate visibility on Twitter due to his established presence on the channel with large numbers of followers, the comparatively smaller population of this avenue (2.5 million Australian users compared with Facebook's 11.5 million; Frank Media 2013) is a considerable weakness in reaching voters and encouraging message distribution through their social networks, even if its popularity among journalists gives it greater inter-media agenda-setting potential (Messner and Garrison 2009: 394). This agenda-setting effect-moving messages from Twitter to mainstream (news organisations) and alternative media (blogs, social media discussions) - has its limitations, however. Rudd's 'selfies', while popular with a younger audience and a useful micro-targeting tactic, could not be controlled in the open context of Twitter and quickly became the subject of some ridicule. Targeted messaging of this type, therefore, is far better employed in social networking services like Facebook, with higher pass-along, but lower visibility to and pick-up by, mainstream media organisations. ${ }^{3}$

Table 1: Comparative party website performance, election 2013

\begin{tabular}{|c|c|c|c|c|c|c|}
\hline & liberal.org.au & alp.org.au & $\begin{array}{l}\text { Ifabbottwinsyoulose. } \\
\text { com.au(ALP) }\end{array}$ & greens.org.au & palmerunited.com & nationals.org.au \\
\hline $\begin{array}{l}\text { Australian } \\
\text { site rank } \\
\text { (popularity) }\end{array}$ & 1,844th & $2,323 \mathrm{rd}$ & 4,475 th & 2,726 th & $6,172 \mathrm{nd}$ & $29,543 \mathrm{rd}$ \\
\hline $\begin{array}{l}\text { Visitors Aug } \\
\text { 1-Sept } 7\end{array}$ & 505,000 & 330,000 & 120,000 & 260,000 & 95,000 & 26,000 \\
\hline $\begin{array}{l}\text { \% referral from } \\
\text { search engine- } \\
\text { July-Sept }\end{array}$ & $39.8 \%$ & $48.2 \%$ & $51.9 \%$ & $35.9 \%$ & $52.3 \%$ & - \\
\hline $\begin{array}{l}\% \text { of search } \\
\text { result paid }\end{array}$ & $13.9 \%$ & $23.7 \%$ & $0.0 \%$ & $0.5 \%$ & $0.0 \%$ & - \\
\hline $\begin{array}{l}\% \text { referral from } \\
\text { social media }\end{array}$ & $16.2 \%$ & $4.8 \%$ & $4 \%$ & $13.1 \%$ & $12.7 \%$ & - \\
\hline \multicolumn{7}{|l|}{ Source: } \\
\hline Facebook & $49.7 \%$ & $72.8 \%$ & $67.9 \%$ & $88.7 \%$ & $98.2 \%$ & - \\
\hline Twitter & $6.6 \%$ & $20.7 \%$ & $11.7 \%$ & $6.1 \%$ & $1.8 \%$ & - \\
\hline Reddit & $0.1 \%$ & $6.2 \%$ & $20.5 \%$ & $4.7 \%$ & $0.0 \%$ & - \\
\hline YouTube & $43.8 \%$ & $0.4 \%$ & $0.0 \%$ & $0.3 \%$ & $0.0 \%$ & \\
\hline
\end{tabular}

Source: Compiled from SimilarWeb data.

2 Unlike in previous national elections, the Liberal's main negative website 'Rudd Facts' was part of their main party domain (www.liberal.org.au/ruddfacts). Traditionally, the parties have distanced their negative/ attack sites from their main campaigning sites with separate domains and non-party branding. 


\section{Raising campaign money through new media}

While professionalisation of management and implementation had clear performance advantages in enhancing the visibility of the established parties, the 2013 election campaign is also instructive in regard to parties learning from campaign experience in other countries and co-opting the strategic repertoires of civil society organisations. The ALP was quite active in recruiting temporary and permanent personnel with experience in international new media campaigning, and experience with the Online Social Movement Organisation (OSMO) GetUp! (Personal interview: Skye Laris, 23 July 2013). The Greens were also very active in drawing on lessons from OSMOs, domestic and international (Personal interview: Rosanne Bersten, 2 August 2013).

The types of lessons drawn ranged from simple engagement strategies (such as providing ready-made 'activist identity' Facebook profile icons on issues like animal rights and same-sex marriage) to more complex ideas about voter engagement, mobilisation and motivation. In the latter area, the Liberal Party and the ALP were particularly interested in developing their 'big data' database analytics capacity for the targeting of direct email, following successes in microtargeting in the United States (Loughnane 2013). Labor and the Greens were invested in 'commitment curve' models of voter engagement that involve working supporters through an increasingly steep set of requests with corresponding feedback and rewards (see Chen 2014).

These rewards included access to information 'first', direct messaging showing the impact of funds provided, and the incorporation of individual narratives in a process of political 'storytelling', adopted directly from the OSMOs (Vromen and Coleman 2013). Pertinent examples of this approach were 'Kevin calls Michelle to say thanks for her \$5 donation' campaign message (about 'Michelle from Bundaberg's' journey from swinging voter to donor out of concern for the implications of an Abbott-led Government; posted 8 August 2013) and Tanya Plibersek's 'Let's clear the air' cigarette plain packing email that linked ALP policy achievements with tobacco industry donations to the Liberal Party (issued 1 August 2013). Similarly, the Greens' 'not in my name' email campaign around asylum seekers was extremely effective in quickly raising money to purchase print media advertising. The Greens have reported that email, rather than other social media, represented the strongest driver for donations (raising 75 per cent of donations; Bersten 2013).

The impact of these types of methods demonstrated considerable benefits to the parties. The ALP, through the use of highly customised, targeted direct email and commitment curve strategies, was able to raise $\$ 800,000$ in smallunit donations during the campaign (Snow 2013), while the Greens' website raised over $\$ 600,000$. This is significant, as the ALP suffered considerable 
problems in fundraising prior to the return of Rudd to the leadership, as its chance of electoral success was perceived as so limited. Overall, therefore, the established parties demonstrated a capacity to enhance both their visibility and strategic capacity during the campaign using their more focused and pragmatic approaches to new media. This compared favourably to parties without these strategies, as was illustrated in Table 1.

\section{Political journalism 2.0: Innovation without impact?}

The Australian news industry has been under considerable economic pressure during the past decade. This is largely due to increased competition for attention and advertising resulting from the expansion of media channels. As established media organisations have begun to substantially reduce their editorial and journalistic workforces in response (Flew and Swift 2013: 195), ${ }^{4}$ the threat of 'churnalism' has been seen as inevitable (Martin and Dwyer 2012). In this case, 'churnalism' has a range of dimensions, including:

- greater use of newswire reports between media (decreasing diversity of content);

- lower editorial standards (decreasing accuracy and parsimony);

- increasing susceptibility to information subsidy (public relations and 'spin'); and,

- a simultaneous deskilling (loss of journalistic specialisations) and upskilling (multi-media journalism, single-person crews, etc.) within the industry.

Because of these implications for practice, the comparative power of media organisations relative to their sources appears to have declined. This has reestablished the relevance of Hall et al.'s (1979: 58) argument that political and party elites (leaders, campaign managers) are more likely to act as 'primary definers' of issues and topics because of their structurally-privileged position relative to alternative sources of interpretative frames. The extent to which this can be seen in the Australian electoral context has relevance for our understanding of the democratic impacts of the political economy of new media. Significantly, as journalists and political elites attempt to exert mutual influence without acquiring dependency (Tiffen 1990), changes in media practice also point to attempts by journalists to free themselves of dependency upon political

4 In the lead-up to the 2013 campaign, the Australian media landscape saw these problems, with up to 30 per cent of staff in News Limited and Fairfax's metropolitan operations laid off in 2012-13. 
elites as primary definers. In the context of the 2013 campaign, we can explore this by looking at the way mainstream news media employed social media, and innovations in the practice of conventional reporting.

\section{Social media, media 'events' and elites}

The integration of social media into journalistic practice has been ongoing for many years (O'Donnell et al. 2013:16). The reasons for this are varied, but include generational change, personal branding, market sensing, and new forms of elite interaction performed in public (Chen 2013). In the 2013 election campaign, the use of social media as part of journalistic practice was highly visible, as illustrated in Figure $1 .^{5}$

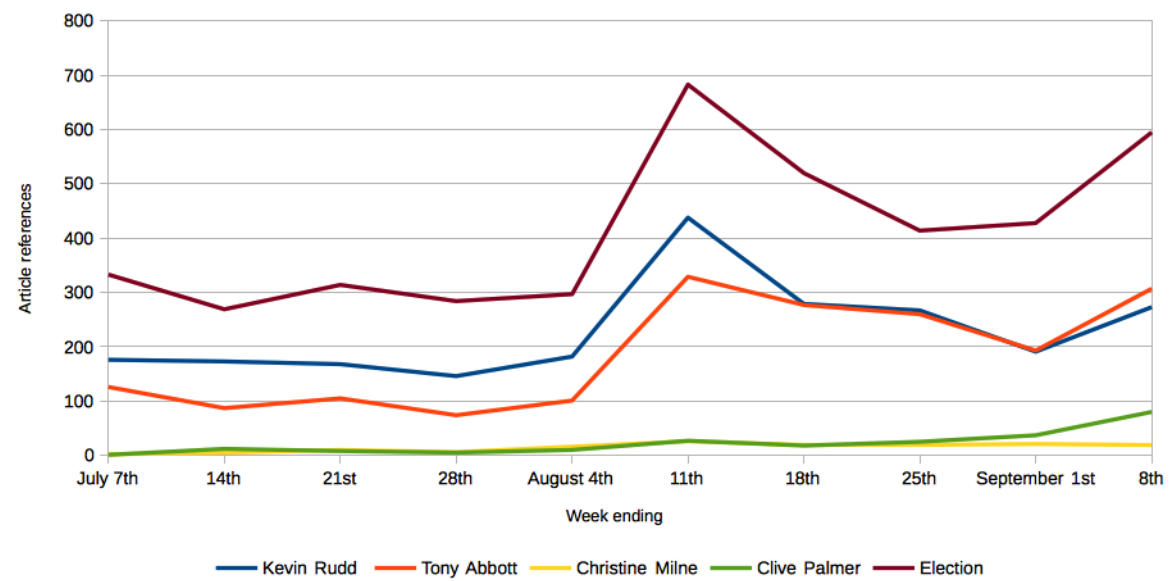

Figure 1: References to social media in political journalism, 2013

Source: Factiva.

This figure, a subset of all print coverage, shows a number of tendencies. First, journalists are selective in the material they import from social media. Thus, Kevin Rudd's tendency to dominate Twitter discussion is not automatically reflected in reporting. While Rudd entered the election with a higher word association with social media than Abbott, the focusing of election coverage on the two leaders quickly reduced this advantage. This also reflects the medium's decreasing novelty, which has reduced the type of strategic meta-coverage that would have previously given Rudd an advantage over Abbott.

5 Based on a search against leaders names and 'Election' and the terms 'twitter', 'tweet', 'facebook', and 'social media'. 
Second, the significant use of social media by minor party leaders receives considerably less media coverage than the two 'parties of government'. This continues to re-affirm Goot's (2009) findings that internet news coverage is narrower than conventional reporting, particularly in its under-reporting of minor parties relative to their vote share. This is a counter-balance to the visibility advantages the Greens have online, and further demonstrates the media logic behind their considerable investment in online channels over many years.

Third, discussion of the political content of social media is not wholly driven by party campaigns, but is now being employed as independent content: journalists are increasingly reporting on events through the lens of social media discussions about them. This has become easier as a range of tools have emerged for tracking trends online, but the focus remains on those social media with the most open publishing platforms, particularly Twitter. Two examples of this are the coverage of popular responses to Tony Abbott's remarks about a candidate having 'sex appeal', leading to the story becoming a top trending topic (\#sexappeal; AFP 2013), and the response to Kevin Rudd's defence of his same-sex marriage position in the final leaders' debate (Knox 2013). Overall, this supports Livingston and Bennett's (2003) hypothesis that the shift towards reporting live events (associated with the constant news cycle and continual publishing) may broaden the source base for journalism.

\section{New news organisations and practices}

The 2013 election campaign saw the emergence of some news organisations with novel (for Australia) business models. Examples include the entry of the Guardian Australia (a non-profit trust) into the Australian market, situating itself to the left of the Fairfax editorial position, as well as the maturation of the non-profit, university-sponsored site The Conversation. During the election period, each performed quite well relative to established media organisations (Table 2) given their comparatively small operating budgets. In addition to these developments, Fairfax extended its paywall model from the Australian Financial Review to its other online properties in mid 2013. 
Table 2: Comparative news organisation website performance, August 2013

\begin{tabular}{|c|c|c|c|}
\hline Website & Type & $\begin{array}{l}\text { Australian site rank } \\
\text { (popularity) }\end{array}$ & August page visits \\
\hline ninemsn.com.au & Commercial & 12th & $28,000,000$ \\
\hline abc.net.au & Public & $21 \mathrm{st}$ & $14,700,000$ \\
\hline news.com.au & Commercial & 40th & $12,700,000$ \\
\hline smh.com.au & Commercial & $41 \mathrm{st}$ & $11,700,000$ \\
\hline theage.com.au & Commercial & 50th & $8,100,000$ \\
\hline heraldsun.com.au & Commercial & $63 r d$ & $6,200,000$ \\
\hline theaustralian.com.au & Commercial & 177th & $3,300,000$ \\
\hline theguardian.co.uk/au & Independent trust & $\mathrm{n} / \mathrm{a}$ & $3,879,200$ \\
\hline dailytelegraph.com.au & Commercial & $133 r d$ & $3,000,000$ \\
\hline crikey.com.au & Commercial & 430th & 930,000 \\
\hline theconversation.edu.au (.com/au) & Non-profit, university & 748th & 930,000 \\
\hline politifact.com.au & Commercial start-up & 24,884 th & 130,000 \\
\hline newmatilda.com & Non-profit & 11,664 th & 40,000 \\
\hline insidestory.org.au & University & 25,439 th & 25,000 \\
\hline 2013electionwatch.com.au & University & 33,879 th & 9,000 \\
\hline
\end{tabular}

Source: Compiled from SimilarWeb data.

While attempts at 'independent' news media websites are not new, one significant new journalistic endeavour during the 2013 campaign was the introduction of branded 'fact-checking' journalism. This idea was imported to Australia from the United States, both in spirit (the ABC set up its internal factchecking organisation with an increase in funding from the Labor Government; The Conversation had a dedicated fact-checking unit for the election) and as a direct licensed version of the original Politifact organisation. ${ }^{6}$ The latter maintained its own site, but syndicated its content to the Fairfax group and the Seven Network (Holmes 2013). As in the US, the visibility of these assessments was quite high in the media organisations that employed them.

An interesting facet of these fact-checking units is not simply their evaluation of political claims as truthful or false, but also in the way these evaluations are presented as evidence-based, with substantiation of claims made. This represents a significant counter to concerns about the decline of journalism into 'churnalism' with limited attention given to complex policy issues and technical points (Phillips 2011). It also contradicts concerns regarding the development of a more assertive style of journalism that moves away from the traditional focus on perceived 'balance' through the provision of equal time to alternative positions.

6 Crikey also started a small fact-checking theme, producing 13 assessments from April 2013 (Knott 2013). 
While there is little evidence of any direct impact of these groups on the conduct of elites during the election (Kevin Rudd, for example, persisted in using a figure of $\$ 70$ million in Coalition cuts after it had been declared false), they mark a response by some media organisations to perceptions that they lack rigour (and therein legitimacy). Moreover, due to marketplace logics, these developments appear to continue into the period of government. As the production and reproduction of news content proliferates between established, emerging, and amateur websites, these types of activities allow rebranding and product differentiation. And, as with the expanded use of polling, factchecking services permit the spontaneous generation of news on demand by media organisations (therein regularising their production processes), and extending coverage of issues with new angles and interpretations.

Overall, it appears that news organisations are embracing new forms of journalistic practice that move away from their dependency on political elites as 'talking heads'. Media organisations also invested more time in collecting and developing data of electoral behaviour and performance during the campaign. This often took the form of data collection (such as the ABC's Vote Compass), data visualisations, maps and interactive explainers. News Limited produced a poll aggregator (the 'Poll Pulse'), while the Australian Financial Review provided a range of visualisations from electoral explainers to leaders' movement maps at its established data journalism sub-domain (www.data.afr.com). These types of initiatives show how established organisations are employing increasingly rich forms of multi-media to present data in interactive and manipulable forms.

\section{Conclusion}

The 2013 federal election was not a competitive race. But the campaign did demonstrate a considerable range of technical and methodological innovation in Australia's political and media landscape that made it a more interesting event than the 2010 election. While the victory of the Coalition will encourage attention to its use of social media and strong cross-channel integration strategies, the effectiveness of small unit fundraising and storytelling strategies by the ALP is also likely to garner considerable attention from party tacticians. Overall, the 2013 campaign shows how quickly and comprehensively the established parties are able to co-opt the technologies and tactics of the online social movement organisations when they see organisational advantage in doing so. This clearly demonstrates the structural and economic advantages of the major parties in the Australian political system, but also the enduring explanatory value of the normalisation hypothesis in broad terms. (For a good example of the significant, but atypical role of new media in equalising competitiveness at the local level, see the arguments of Costar and Curtin in this volume.) The lessons for the news 
media are less clear, but the range of new journalistic practices deployed for the 2013 election demonstrates how media organisations are moving beyond reactive strategies associated with downsizing and withdrawal, to examining new ways to engage media audiences and produce higher quality output.

\section{References}

Agence France-Presse (AFP). 2013. 'Australia's Abbott in "sex appeal" blunder' . Capital News, 13 August: <www.capitalfm.co.ke/news/2013/08/australiasabbott-in-sex-appeal-blunder/>.

Bersten, Rosanne. 2013. 'Digital and Social Media: 2013 Federal Election Analysis', 16 November.

Chen, Peter John. 2005. 'The new media: E-lection 2004?' In Marian Simms and John Warhurst (eds), Mortgage Nation: the 2004 Australian Election, Perth: API Network.

Chen, Peter John. 2008. 'Australian political parties' use of Youtube 2007'. Southern Review: Communication, Politics and Culture 41(1): 114-41.

Chen, Peter John. 2012. 'The new media and the campaign'. In Marian Simms and John Wanna (eds), Julia 2010: The caretaker election, Canberra: ANU E-Press.

Chen, Peter John. 2013. Australian Politics in a Digital Age. Canberra: ANU E-Press.

Chen, Peter John and Walsh, Lucas. 2010. 'e-lection 2007? Political competition online'. Australian Cultural History 28(1): 47-54.

Chen, Peter John. 2014. 'The virtual party on the ground'. In Anika Gauja, Narelle Miraglotta and Rodney Smith (eds), Resilient and Defiant: Reflections on Contemporary Party Organisations, Melbourne: Monash University Press, in-press.

Flew, Terry and Swift, Adam. 2013. 'Regulating journalists? The Finkelstein Review, the Convergence Review, and news media regulation in Australia'. Journal of Applied Journalism and Media Studies 2(1): 181-99.

Frank Media. 2013. Social Media Statistics Australia-April 2013, viewed 15 January 2014: <frankmedia.com.au/2013/05/01/social-media-statisticsaustralia-april-2013/>. 
Gibson, Rachel. 2002. 'Virtual campaigning: Australian parties and the impact of the internet'. Australian Journal of Political Science 37(1): 99-130.

Gibson, Rachel and Cantijoch, Marta. 2011. 'Comparing online elections in Australia and the UK: Did 2010 finally produce "the" internet election?' Communication, Politics \& Culture 44(2): 4-17.

Gibson, Rachel and McAllister, Ian. 2011. A net gain? Web 2.0 campaigning in the Australian 2010 election. Paper prepared for presentation at the 2011 Annual Meeting of the American Political Science Association, Seattle.

Gibson, Rachel and Ward, Stephen. 2003. 'Letting the daylight in? Australian state parties and the WWW'. In Rachel Gibson, Paul Nixon and Stephen Ward (eds), Net Gain? Political Parties and the Internet. London, UK: Routledge.

Goot, Murray. 2009. 'Is the news on the internet different? Leaders, frontbenchers and other candidates in the 2007 Australian election'. Australian Journal of Political Science 43(1): 99-110.

Grant, Will, Moon, Brenda, and Grant, Janie. 2010. 'Digital dialogue? Australian politicians' use of the social network tool twitter'. Australian Journal of Political Science 45(4): 579-604.

Hall, Stuart, Critcher, Chas, Jefferson, Tony, Clarke, John, and Roberts, Brian. 1979. Policing the Crisis: Mugging, the State and Law and Order. London, UK: Macmillan.

Hobbs, Matt, Khaleeli, Mahnaz, and Stone, Merlin. 2003. 'Multi-channel customer management'. In Neil Woodward, Merlin Stone and Bryan Foss (eds), Customer Management Scorecard: Managing CRM for Profit, London, UK: Kogan Page.

Holmes, Jonathan. 2013. 'Truth trivial in an election: now there's a fact'. The Sydney Morning Herald, 21 August, viewed 15 January 2014: <www.smh. com.au/federal-politics/federal-election-2013/truth-trivial-in-an-electionnow-theres-a-fact-20130820-2s92b.html>.

Kaplan, Andreas and Haenlein, Michael. 2010. 'Users of the world, unite! The challenges and opportunities of Social Media'. Business Horizons 53(1): 5968.

Knott, Matthew. 2013. 'Fact off: ABC and Fray's PolitiFact dig into pollies' spin'. Crikey, 29 April, viewed 1 October 2013: <www.crikey.com.au/2013/04/29/ fact-off-abc-and-frays-politifact-dig-into-pollies-spin $>$, accessed: 1/10/13. 
Knox, David. 2013. 'Kevin Rudd defends gay marriage position. "It is how people are built"'. TV Tonight, 3 September, viewed 15 January 2014: <www. tvtonight.com.au/2013/09/kevin-rudd-defends-gay-marriage-position-it-ishow-people-are-built.html>.

Livingston, Stephen and Bennett, W Lance. 2003. 'Gatekeeping, indexing, and live-event news: Is technology altering the construction of news?'. Political Communication 20: 363-80.

Loughnane, Brian. 2013. 'Address to the National Press Club'. Canberra, 23 October, viewed 26 October 2013: <lpaweb-static.s3.amazonaws. com/Brian \% 20Loughnane \% 20-\%20National \% 20Press \% 20Club \% 20 Address \%20-\%2023\%20October \%202013.pdf>.

Macnamara, Jim and Kenning, Gail. 2011. 'E-electioneering 2010: Trends in social media use in Australian political communication'. Media International Australia 139: 7-22.

Martin, Fiona and Dwyer, Tim. 2012. 'Churnalism on the rise as news sites fill up with shared content and wire copy'. The Conversation, 25 June, viewed 15 January 2014: <theconversation.com/churnalism-on-the-rise-as-newssites-fill-up-with-shared-content-and-wire-copy-7859>.

Messner, Marcus and Garrison, Bruce. 2009. 'Internet communication'. In Don Stacks and Michael Salwen (eds), An Integrated Approach to Communication Theory and Research, 2nd edn, New York: Routledge.

O'Donnell, Penny, McKnight, David and Este, Jonathan. 2012. Journalism at the Speed of Bytes: Australian Newspapers in the 21st Century. Sydney: Media, Entertainment and Arts Alliance.

Phillips, Angela. 2011. 'Transparency and the new ethics of journalism'. In Bob Franklin (ed.), The Future of Journalism, London: Routledge.

Sadauskas, Andrew. 2013. '57\% of Australians have smartphones, adoption rates outpace the US and Europe'. Smart Company, 17 May, viewed 15 January 2014: <www.smartcompany.com.au/information-technology/049727-57-ofaustralians-have-smartphones-adoption-rates-outpace-the-us-and-europe. html>.

Small, Tamara. 2008. 'Equal access, unequal success: Major and minor Canadian parties on the net'. Party Politics 14: 51-70. 
Snow, Deborah. 2013. 'How Kevin Rudd's 2013 election campaign imploded'. The Sydney Morning Herald, 9 September, viewed 15 January 2014: <www. smh.com.au/federal-politics/federal-election-2013/how-kevin-rudds-2013election-campaign-imploded-20130908-2tebl.html>.

Tiffen, Rodney. 1990. News and Power. Sydney: Allen \& Unwin.

Vromen, Ariadne and Coleman, William. 2013. 'Online campaigning organizations and storytelling strategies: GetUp! in Australia'. Policy and Internet 5(1): 70-100.

Wright, Jessica. 2012. 'Liberal gag twits'. The Sydney Morning Herald, 9 December, viewed 15 January 2014: <www.smh.com.au/technology/ technology-news/liberals-gag-twits-20121208-2b284.html $>$. 
This text taken from Abbott's Gambit: The 2013 Australian Federal Election, edited by Carol Johnson and John Wanna, published 2015 by ANU Press, The Australian National University, Canberra, Australia. 